\title{
CONTATOS COM A HISTÓRIA NO CONTO QUANDO O SENHOR PIRZADA VINHA JANTAR
}

\section{CONTACTS WITH HISTORY IN THE SHORT STORY WHEN MR. PIRZADA CAME TO DINE}

\author{
Dionei Mathias ${ }^{1}$ \\ Juliana Müller ${ }^{2}$
}

Recebido em: 17 dez. 2019.

Aceito em: 02 mai. 2020

DOI 10.26512/aguaviva.v5i2.28703

\begin{abstract}
RESUMO: Este artigo pretende discutir duas formas de contato com os acontecimentos históricos presentes no conto Quando o Senhor Pirzada vinha jantar, escrito por Jhumpa Lahiri em 1999 e presente na coletânea Intérprete de Males. O conto em questão retrata as experiências de uma criança chamada Lilia, filha de pais indianos e que cresce nos Estados Unidos. $\mathrm{O}$ primeiro vetor de seu relacionamento com os acontecimentos históricos foca no contexto de origem da família de Lilia, enquanto o segundo está interessado em discutir sua socialização com a história americana, mediada por uma escola nos Estados Unidos. Nos dois contextos, Lilia dialoga com a história e se posiciona, ao identificar diferentes formas de pertencimento, inscritas em narrativas históricas. Para essa finalidade, são relevantes aqueles eventos históricos que fornecem sentido à narrativa de identidade da protagonista.
\end{abstract}

PALAVRAS-CHAVE: Jhumpa Lahiri. Interpreter of Maladies. When Mr. Pirzada came to dine. História. Identidade.

\begin{abstract}
This article aims to analyse two kinds of contact with historical events in the short story "When Mr. Pirzada came to dine", written by Jhumpa Lahiri in 1999 and part of the collection Interpreter of Maladies. The short story at issue portrays the experiences of a child called Lilia, born to Indian immigrants and growing up in the United States. The first vector of her involvement with historical events focuses on the context of origin of Lilia's parents, whereas the second is interested in discussing her socialization with American history, as

\footnotetext{
${ }^{1}$ Professor de língua e literatura na Universidade Federal de Santa Maria. Possui formação em Letras pela Universidade de Hamburgo (Grund- und Hauptstudium, Magister Artium, Doktor phil.) e pela Universidade Federal do Paraná (Doutorado em Letras). E-mail: dioneimathias@gmail.com

${ }^{2}$ Graduanda do curso de Letras - Inglês e suas Literaturas na Universidade Federal de Santa Maria. Participou do projeto "Margens e minorias na literatura" durante o segundo semestre de 2018. Atualmente participa do projeto "Literatura e Identidade". E-mail: juju-1232@ @otmail.com
} 
mediated by a school in the USA. In both contexts, Lilia relates to history and positions herself by identifying different forms of belongingness, inscribed in historical narratives. For this purpose, those historical events are relevant which provide meaning for the main character's identity narration.

KEYWORDS: Jhumpa Lahiri. Interpreter of Maladies. When Mr. Pirzada came to dine. History. Identity.

\section{INTRODUÇÃO}

O conto Quando o Senhor Pirzada vinha jantar faz parte da coletânea Interpreter of Maladies, publicada em 1999 e vencedora do Prêmio Pulitzer, no ano seguinte. Escrita por Jhumpa Lahiri, filha de imigrantes bengaleses, a coletânea reúne textos que, cada um em si, apresentam registros da experiência de fluxos migratórios (MATHIAS, 2018). Com isso, Jhumpa Lahiri se junta a uma série de outras vozes, cujos interesses se voltam para as experiências de atores sociais, ou neste caso, de personagens ficcionais com algum elo de ligação com o continente asiático. O esforço dessas diferentes vozes reside em imaginar esses indivíduos em seu novo contexto de interação na sociedade americana, problematizando formas de pertencimento, narrativas de identidade e concepções de si.

Na produção discursiva dos estudos literários, esse campo de pesquisa veio a receber a etiqueta de "Asian American Literature" (Adams, 2008), um campo portanto que reúne e discute uma diversidade de experiências socioculturais, incluindo atores sociais vindos por exemplo da China, do Japão, da Índia, do Paquistão ou do Bangladesh, para construir uma nova existência nos Estados Unidos. Muitos desses textos discutem primeiramente a condição de imigrante e suas implicações para a concretização de uma identidade. Ao mesmo tempo, contudo, eles também empreendem um esforço para pensar uma nova forma de conceber a narrativa nacional americana. Em ambos os casos, impera uma dupla vetorialidade na afiliação discursiva e afetiva.

O conto em questão encena as experiências de Lilia, uma criança em idade escolar, a qual se vê confrontada com vetores da história, em dois contextos culturais diversos. Por um lado, ela assimila informações mediadas pelos noticiários americanos sobre os conflitos no subcontinente indiano, os quais levam à gênese de Bangladesh. Por outro lado, ela aprende na escola a rememorar a gênese da fundação do estado americano. As narrativas históricas no subcontinente indiano são de grande importância para os pais e para o visitante Mr. Pirzada, a 
narrativa americana tem relevância para seus colegas de aula e para o contexto da sociedade em que circula. Desse modo, Lilia se vê confrontada com uma experiência recorrente em contextos de fluxos migratórios, a saber, a produção de sentidos a partir de dois contextos culturais diversos.

No percurso da socialização cultural, a história nacional surge, em algum momento, no horizonte identitário de cada indivíduo. Há sociedades que atribuem grande importância à macronarrativa nacional, prevendo datas de comemoração e estágios de iniciação à história nacional. Em outras sociedades - muitas vezes ainda em processo de construção de uma narrativa nacional - esses rituais vão se consolidando com a estabilização de uma identidade que representa a nação. Esses elementos da história acabam tendo um impacto também sobre a identidade pessoal do sujeito e no modo como constrói sentidos a partir dessas malhas, identificando para si uma localização sociocultural e adotando uma afiliação a uma macronarrativa histórica que lhe servirá de base nas dinâmicas de representação dentro na própria nação ou no plano internacional.

Em seu importante estudo sobre a história, Straub (2005, p. 44-45) cria uma interessante interseção entre identidade pessoal e pensamento histórico:

Our historical consciousness often shapes our autobiographical accounts and self-understanding quite directly. We understand both what happens to us and the attitude we assume toward it historically; we understand our present situation, our present activity or inactivity, and finally our plans for the future, in part historically. The same holds for how we understand others. But what does it actually mean to understand oneself, one's world, and the world of others historically? What is the historical construction of meaning? What is historical thought? What does it even mean to regard the world, oneself, and others - as yet prior to any particular intellectual claims - as historical reality? (STRAUB, 2005, p. 44-45). ${ }^{3}$

\footnotetext{
${ }^{3}$ Nossa consciência histórica frequentemente modela nossas considerações autobiográficas e auto-entendimento quase diretamente. Nós entendemos o que acontece conosco bem como a atitude que assumimos historicamente; nós entendemos nossa situação presente, nossa presente atividade ou inatividade, e finalmente nossos planos para o futuro, em parte historicamente. O mesmo se aplica para como entendemos os outros. Mas o que exatamente significa entender a si mesmo, seu mundo, e o mundo de outros, historicamente? O que é a construção histórica de sentido? O que é pensamento histórico? O que mesmo significa perceber o mundo, a si mesmo, aos outros - como ainda anterior a qualquer pretensão intelectual - como realidade histórica? (STRAUB, 2005, p. 44-45).
} 
$\mathrm{O}$ argumento central parece residir no fato de que o condicionamento histórico tem um impacto no modo como identidades são percebidas e construídas pelo indivíduo. Isso significa que os vetores de sentidos que formam a base daquilo que posteriormente acaba sendo denominado de identidade resulta também de um crivo histórico, o qual define como o sujeito vai se apropriar do mundo e construir suas realidades. Esse esforço de construção de identidade parece estar atrelado aos valores que uma sociedade acolhe e nutre, produzindo sentidos de acordo com os parâmetros daquele momento.

Com efeito, o condicionamento histórico define as narrativas aceitáveis e produzíveis num determinado contexto de interação social. Com isso, a socialização sociocultural com suas narrativas históricas (nacionais) também define como o sujeito se enxerga e se posiciona no mundo, especialmente na questão de pertencimento. Se dentro de uma tradição histórica, com a narrativa de grupo e de nação, isso já é complicado, essa situação se torna ainda mais complexa quando os atores sociais apresentam afiliações duplas, como é o caso de atores sociais em contextos migratórios. Essa complexidade se origina no fato de que há duas tessituras históricas que impactam sobre a visão de mundo do sujeito e duas tessituras que ele como ator social precisa alimentar ou descartar.

O conto de Jhumpa Lahiri problematiza essa interseção da experiência humana, ao encenar como a criança Lilia, em seu percurso de socialização sociocultural, acaba envolvida com duas tessituras históricas que, de algum modo, influenciam seus movimentos de autoconcepção e de negociação de narrativas identitárias. Ao construir seu mundo ou sua realidade pessoal, a criança Lilia começa a atribuir sentidos às diferentes informações processadas por ela. Nesse sentido, este artigo deseja discutir dois vetores: por um lado, o relacionamento com os acontecimentos históricos do contexto de origem da família, por outro, sua socialização com a história americana, no âmbito da escola. Nas duas situações, a protagonista começa a se posicionar e a identificar formas de pertencimento a partir das narrativas históricas.

\section{Turbulências políticas no país de origem dos pais}

O interesse de Lilia por acontecimentos históricos e por seu impacto na gênese de sentidos se vê despertado com a chegada do visitante Sr. Pirzada, um estudioso da região de Bangladesh em viagem de estudos aos Estados Unidos, que acaba visitando a família de Lilia, com frequência, dadas as afinidades culturais com os pais da menina. Reunidos em volta da 
mesa e em frente à televisão, Sr. Pirzada e os pais de Lilia discutem as turbulências políticas que acometem os subcontinentes indianos. Lilia testemunha essas conversas e as imagens veiculadas pela televisão, começando a refletir sobre seu lugar de pertencimento. Até aquele momento, essas informações não tinham relevância em seu universo infantil. Com a chegada do visitante, ocorre um despertar para a consciência histórica.

O contato com os acontecimentos históricos do contexto de origem da família de Lilia, que faz parte da segunda geração de imigrantes "presos entre a cultura dos pais, a qual eles não conhecem, e a cultura hospedeira em que nascem e são criados" (DURAIRAJ, 2018, p. 79) ${ }^{4}$, se dá a partir de dois eixos: o primeiro está relacionado com as informações provindas dos pais, enquanto o segundo provém de informações transmitidas por noticiários americanos. A criança ainda vive em um universo infantil, interessada, sobretudo, em um excerto da realidade mais voltado para os aspectos lúdicos e menos sintonizado para questões políticas que interessam os adultos. É a partir dos discursos de sua família e de notícias midiáticas que ela passa a ter seu interesse despertado, começando a perceber a existência de diferentes identidades nacionais: "Agora que eu sabia que o sr. Pirzada não era indiano, comecei a estudá-lo com mais cuidado, tentando entender o que o tornava diferente" (LAHIRI, 2014, p. 38). A partir desse interesse, ela começa a organizar os dados percebidos para construir uma outra imagem da realidade, a qual também desperta um certo grau de consciência sobre seu posicionamento histórico e cultural.

Essa habilidade perceptiva se desenvolve a partir das discussões que a menina vivencia em seu microcosmo familiar. Por um lado, a família provoca sua imaginação com experiências vividas num lugar distante e, por outro, as mídias veiculam acontecimentos atuais que têm impacto nas vidas dos outros membros de sua família. Antes disso, esses acontecimentos tinham pouca relevância em seu universo, de modo a não suscitar qualquer interesse em traçar distinções culturais ou históricas. Esse estado de percepção está atrelado primeiramente a sua faixa etária, naturalmente menos interessada em questões políticas. Ao mesmo tempo, contudo, também está conectado com o contexto em que a criança se insere, visto que este está mais voltado para o reconhecimento de traços da identidade nacional americana, e menos focado em outras narrativas nacionais. Até aquele momento, o exercício de agrupamento por semelhança

\footnotetext{
4، trapped between their parent's culture which they are not aware of and the host culture in which they are born and brought up" (DURAIRAJ, 2018, p. 79).
} 
cultural e histórica não existia em sua consciência como estratégia cognitiva de apropriação de mundo. Com a chegada do Sr. Pirzada, Lilia começa a alocar indivíduos com características parecidas a um mesmo grupo, identificando que estes têm experiências e passados comuns.

O primeiro eixo relacionado com os acontecimentos históricos é gerenciado principalmente pelo pai da criança, que a confronta com algumas informações desconhecidas para ela. Assim, Lilia é confrontada com uma realidade que ela não entende, visto que o contexto em que a menina vive não a socializa para as questões relevantes nos países asiáticos. A realidade em questão se refere ao evento conhecido como Partição, que reconfigurou as linhas demarcatórias entre a Índia, o Paquistão e Bangladesh. Lilia começa a desenvolver uma consciência sobre isso por intermédio da figura paterna. Assim, quando Lilia se refere ao senhor Pirzada como um homem indiano, o pai a corrige explicando que: “[...] o senhor Pirzada não se considera mais indiano - meu pai anunciou, espanando o sal das castanhas da barba preta aparada. - Desde a partição. Nosso país foi dividido" (LAHIRI, 2014, p. 33). Na visão da menina, não fazia sentido que o senhor Pirzada não fosse indiano, visto que ele e os pais de Lilia falavam a mesma língua, riam das mesmas piadas e tinham uma fisionomia parecida. As conversas e a problematização, ambas suscitadas pelo pai, iniciam uma atividade interessada em entender as motivações para distinguir diferentes identidades nacionais.

Ao perceber que a filha não sabe nada sobre a Partição da Índia, o pai fica desconcertado, tendo em vista que ele esperava que ela conhecesse eventos históricos relacionados com a origem dos seus progenitores: “- Mas o que ela sabe do mundo? - Meu pai chacoalhou a lata de castanhas na mão. - O que ela está aprendendo?” (LAHIRI, 2014, p. 35). Com efeito, a expectativa do pai é desproporcional e destoa da realidade, já que a menina é condicionada a aprender fatos sobre o país em que mora. Para Rajesh e Rajaram (2014, p. 122), “os pais de Lilia estão frustrados com a ignorância dela sobre os acontecimentos atuais em sua terra natal - o subproduto de sua escolaridade na América"5. Cabe a ele então mostrar um pouco da sua própria história para a filha. Nisso, ele opta por indicar, sobretudo, a arbitrariedade do acontecimento referido como a Partição da Índia: "Num momento a gente estava livre, no outro partido em dois - explicou, fazendo um X com o dedo na bancada -, como uma torta. Hindus aqui, muçulmanos aqui. Daca não pertence mais a nós” (LAHIRI, 2014, p. 33). Embora Lilia

\footnotetext{
5“'Lilia's parents are frustrated by her ignorance of current events in their homeland - the byproduct of her schooling in America" (RAJESH; RAJARAM, 2014, p. 122).
} 
não reflita sobre isso, a interpretação de realidade empreendida pelo pai dá início a um processo de sensibilização que indica a necessidade de questionar o condicionamento histórico, no qual o indivíduo se vê inserido.

O segundo eixo, gerenciado por notícias midiáticas, confronta Lilia com as imagens do conflito existente entre o triângulo composto por Índia, Paquistão e Bangladesh: "Na tela, vimos tanques rodando por ruas poeirentas, edifícios destruídos, florestas de árvores desconhecidas onde os refugiados paquistaneses orientais tinham de se abrigar, buscando segurança além da fronteira indiana" (LAHIRI, 2014, p. 39). A jovem tem seu interesse despertado por essa realidade por causa do pai, que insiste para que ela assista ao noticiário junto dele, da mãe e de Sr. Pirzada. Antes do pedido do pai, ela se ocupava com outras tarefas. Apesar de assistir ao noticiário, ela não consegue compreender os acontecimentos, visto que é confrontada com algo muito distante daquilo que já vivenciou: "Discutiram intrigas que eu não conhecia, uma catástrofe que eu não conseguia entender. - Está vendo, crianças da sua idade, o que precisam fazer para sobreviver - meu pai disse enquanto me servia outro pedaço de peixe" (LAHIRI, 2014, p. 39). O pai de Lilia busca provocar a filha com a temática, relatando o que crianças da idade dela enfrentam dia a dia, porém ela ainda não desenvolveu uma consciência sobre isso, já que sua socialização se deu em uma cultura totalmente diferente, em que ela não enfrenta esses problemas.

A partir do contato com as informações midiáticas, a menina passa a criar um início de consciência sobre a existência dessas outras formas de realidade. Com a complicação da situação conflituosa entre Índia, Paquistão e Bangladesh, Lilia começa a reconhecer uma realidade mais sombria, relacionada também com a censura: "Com o passar das semanas, foi ficando cada vez mais raro ver imagens de Daca no noticiário. A reportagem vinha depois do primeiro intervalo comercial, às vezes do segundo. A imprensa tinha sido censurada, removida, restringida, redirecionada" (LAHIRI, 2014, p. 41). A partir dessa experiência, ela toma conhecimento de uma realidade em que os países se fecham, proibindo a divulgação de notícias sobre os conflitos que afligem seus cidadãos. Paulatinamente, surge uma narrativa histórica que afeta sua visão de realidade, produzindo novas redes de sentidos em que ela tenta compreender aquilo que os pais e o Sr. Pirzada vivenciaram, visto que "somente após esses incidentes ela 
reconhece a dor dos imigrantes indianos da primeira geração como o Sr. Pirzada" (DURAIRAJ, 2018, p. 80) ${ }^{6}$.

Ainda com relação às notícias midiáticas, a jovem também é confrontada com a realidade da guerra e da violência: "A guerra foi declarada oficialmente em 4 de dezembro e, doze dias depois, o Exército paquistanês, enfraquecido por ter de lutar a quase cinco mil quilômetros de sua fonte de suprimentos, se rendeu em Daca" (LAHIRI, 2014, p. 48). Para a gênese de sua consciência histórica, contudo, importa menos o impacto das imagens, mas sim, o que elas produzem sobre os outros atores sociais que circulam em sua casa. Ela percebe que há uma alteração afetiva na configuração do microcosmo em que está inserida. Seus pais e Mr. Pirzada mudam seu modo de agir, e até mesmo as refeições compartilhadas entre o grupo não apresentam mais a mesma configuração. Ela volta sua atenção para o noticiário, mas continua não compreendendo as implicações dos acontecimentos bélicos:

O que eu me lembro daqueles doze dias de guerra é que meu pai não me pedia
mais para assistir ao noticiário com eles, que o sr. Pirzada parou de me trazer
doces, que minha mãe se recusava a servir qualquer outra coisa além de ovos
cozidos no jantar. [...] Acima de tudo, me lembro dos três agindo durante essa
época como se fossem uma só pessoa, compartilhando uma única refeição, um
único corpo, um único silêncio, um único medo (LAHIRI, 2014, p. 48).

Lilia percebe que há uma tentativa de preservá-la, visto que o pai para de insistir para que ela veja as notícias. A menina também percebe que os três adultos passam a agir como se fossem um só, mostrando que apesar de estarem em grupos diferentes e serem de países diferentes, eles sentem os mesmos temores com relação à situação em que os três países estão inseridos. O que Lilia apreende nessa situação é a alteração na configuração afetiva, desencadeada por eventos históricos que afetam sua família. Ela se dá conta que eles são responsáveis pela formação de malhas de sentidos, no cerne de sua família. Com base nessa observação, sua consciência histórica começa a se formar e produzir sentido em seu próprio universo pessoal.

\footnotetext{
6 "It is only after these incidents she recognizes the pain of the first generation Indian immigrants like Mr.Pirzada" (DURAIRAJ, 2018, p. 80).

${ }^{7}$ Tradução nossa do original em língua inglesa.
} 
Por fim, com o término do conflito entre Índia, Paquistão e Bangladesh, o senhor Pirzada retorna a seu país de origem, reencontrando as filhas e a esposa. Por meio do noticiário, Lilia recebe a informação sobre a criação de uma nova nação: "Segundo as reportagens, Daca estava se recuperando devagar, com um governo recém-formado. [...] De vez em quando, eu estudava o mapa acima da mesa de meu pai e imaginava o sr. Pirzada naquele pedacinho amarelo [...]" (LAHIRI, 2014, p. 49). Antes de ser confrontada com diferentes visões de mundo, ela não conseguia compreender a divisão entre Índia e Paquistão no mapa mundi que seu pai possuía - para ela, não havia divisão nenhuma. Ao final do percurso traçado pelo conto, o mapa deixa de ser somente um desenho com demarcações, para se transformar em símbolo que contém narrativas da história nacional que impactam, em forma de sentido, sobre a existência individual. Nesse processo, Lilia dá início à gênese de consciência sobre suas próprias ligações com a Ásia e sobre o lugar da história em sua própria narrativa de identidade.

\section{Socialização histórica no contexto americano}

O contato que Lilia tem com acontecimentos históricos no país de origem de seus pais praticamente se limita às informações transmitidas no cerne da família ou por meio de veículos de comunicação. Isso muda substancialmente no que concerne ao contato com a história americana. A socialização de Lilia, nascida e criada nos Estados Unidos, ocorre no contexto institucional da escola em que ela estuda. Nela, a menina é confrontada com acontecimentos importantes para a macronarrativa daquele país:

Nós aprendíamos história americana, claro, e geografia americana. Naquele ano e em todos os anos, aparentemente, começávamos estudando a Revolução Americana. Éramos levados em ônibus da escola a excursões para visitar Plymouth Rock e caminhar pela Trilha da Liberdade, escalar até o alto do monumento Bunker Hill. Construíamos dioramas de papel colorido mostrando George Washington atravessando as águas encapeladas do rio Delaware e fazíamos fantoches do rei George usando calça branca apertada e um arco preto no cabelo (LAHIRI, 2014, p. 35). ${ }^{8}$

O foco de aprendizagem da menina está naturalmente focado na gênese da nação americana, excluindo outras narrativas nacionais desse ciclo de aprendizado. Assim a Partição, que é abordada pelo pai e que lhe causa desconforto por não possuir qualquer conhecimento

\footnotetext{
${ }^{8}$ Tradução nossa do original em língua inglesa.
} 
sobre seu significado, não figura no currículo das crianças americanas. Com efeito, há uma ênfase substancial em assuntos relevantes para a narrativa da nação, o que contribui para estabelecer e fixar uma identidade nacional sólida nas crianças. Com isso, a instituição da escola desenvolve um trabalho de peso no sentido de desenvolver uma consciência histórica nas crianças, situando-as dentro dessas narrativas e estimulando-as à identificação. Para isso, o foco acaba ficando restrito ao contexto americano, excluindo do currículo outros elementos do conjunto de fatos históricos que poderiam ser relevantes para a formação no contexto escolar. Os passeios e os elementos lúdicos facilitam esse trabalho de identificação e cria um conjunto de experiências que forma a base de uma configuração afetiva positiva que no processo de inserção do cidadão nas malhas sociais tem um impacto a longo prazo.

As avaliações realizadas pela professora Kenyon - como importantes instrumentos institucionais de fixação - não têm o objetivo primário de estimular o pensamento crítico dos alunos, mas sim de assegurar que os elementos importantes da narrativa histórica nacional foram adequadamente internalizados: "Nas provas, nos davam mapas em branco das treze colônias para colocarmos os nomes, as datas e as capitais. Eu sabia fazer isso de olhos fechados" (LAHIRI, 2014, p. 35). Nesse contexto, as crianças são treinadas a memorizarem determinados conhecimentos que sejam substanciais para a ideia de uma identidade nacional. Como em muitos outros currículos nacionais, as crianças não são confrontadas com narrativas da história que transcendam seu contexto de socialização.

Lilia, contudo, representa uma exceção, já que faz contato com outras identidades nacionais, abandonando, dessa forma, as coordenadas seguras de uma narrativa homogênea e única. As vivências relatadas pelos pais e a visita do Sr. Pirzada lhe permitem vislumbrar a concretização da história em outra parte do mundo. Através da guerra acompanhada no noticiário e discutida pelos pais e por senhor Pirzada a menina percebe que os acontecimentos não têm relação com o país em que vive. Ela também se dá conta que esses acontecimentos de grande significância para os outros membros de sua família são completamente ignorados no ambiente escolar: "Ninguém na escola comentou a guerra acompanhada tão fielmente na minha sala de estar. Continuamos a estudar a Revolução Americana e aprendemos sobre a injustiça dos impostos sem representação e memorizamos passagens da Declaração da Independência" (LAHIRI, 2014, p. 35). Apesar da importância dos eventos para sua família, estes não são abordados em forma de discussão ou, ao menos, de reconhecimento de seu impacto para a 
família da aluna. "Entre a tradição de seus pais e a cultura americana" (BASAK, 2018, p. 23) 9 , Lilia está diante de uma situação em que o conhecimento fornecido no contexto escolar não supre suas necessidades e tampouco reconhece suas aflições.

A partir do total apagamento da existência da guerra, a menina é tomada por um ímpeto de curiosidade, indo além daquilo que lhe é exigido pela professora, a saber pesquisar sobre um aspecto da Revolução Americana. Ao tentar buscar conhecimentos sobre o país de origem de seus pais, contudo, Lilia é desencorajada por ela. Assim, a senhora Kenyon chama sua atenção, ao perceber que o livro que tem em mãos não faz parte da bibliografia exigida para o trabalho escolar. O desvio de foco é imediatamente punido, a fim de que a menina volte a investir sua energia intelectual na pesquisa sobre a rendição em Yorktown, elemento importante da Revolução Americana: "Então não vejo razão para você estar consultando isto - disse, recolocando-o no espaço da estante. - Você vê?” (LAHIRI, 2014, p. 41). Este fragmento reforça a ideia de que não há espaço para narrativas que extrapolem o eixo nacional. Com a passagem pela instituição escolar, Lilia precisa se contentar com as formatações discursivas previstas naquele currículo.

No contexto em que Lilia está inserida, a escola deixa de ser um espaço que provoca o confronto de ideias e o estímulo ao pensamento crítico dos alunos. De certo modo, limita-se ao treinamento da identidade nacional, em que os alunos são expostos de forma repetitiva a determinados conteúdos, considerados substanciais para aquela narrativa. A internalização desses conhecimentos vai garantir a elegibilidade para o pertencimento a essa nação. Esse modelo de interação volta até mesmo nos momentos de lazer das crianças: "Durante o intervalo, os meninos se dividiram em dois grupos, um perseguindo loucamente o outro em torno dos balanços e gangorras, Casacos Vermelhos contra as colônias" (LAHIRI, 2014, p. 40). Assim, através das brincadeiras no pátio da escola, a internalização da identidade nacional volta a ser treinada, deixando Lilia num limbo de pertencimento. Pois, embora se identifique também com essas narrativas, há outras que lhe são igualmente importantes. Estas, contudo, não tem espaço de articulação no contexto institucional da escola.

Desse modo, o processo de socialização histórica mediado pela escola ocorre em duas etapas: a de exposição e a de treinamento. A primeira etapa se baseia na transmissão de

\footnotetext{
9 "Lilia is caught between the tradition of her parents and American culture" (BASAK, 2018, p. 23).
} 
conhecimentos considerados substanciais e na repetição dos mesmos, para que eles sejam internalizados pelos alunos, que a partir da visão da instituição, precisam aprender fatos e elementos a fim de perceberem a qual identidade nacional pertencem. Já a segunda etapa, a de treinamento, está atrelada aos exercícios que os alunos fazem de forma consciente ou inconsciente. As atividades avaliativas constituem exercícios feitos conscientemente, visto que os alunos precisam mostrar o domínio de conhecimentos sobre o próprio país, como nomear estados e ler mapas, além de realizarem pesquisas semanais sobre algum tópico do conteúdo estudado. Como exercício inconsciente é possível destacar o momento de lazer das crianças que, durante o intervalo, encenam episódios da Revolução Americana por diversão e de forma inocente, sem perceberem as lógicas de pertencimento inerentes ao momento lúdico.

Através dos conhecimentos transmitidos pela escola e daquilo que é ensinado por seus pais, Lilia passa a desenvolver consciência histórica. Ela percebe nesse contexto como seu pertencimento também está condicionado às narrativas históricas, nas quais é socializada. Isso fica claro na resposta da mãe às críticas da figura paterna:

- Lilia tem muita coisa para aprender na escola - minha mãe falou. - Nós agora moramos aqui, ela nasceu aqui. - Parecia genuinamente orgulhosa do fato, como se fosse uma reflexão sobre meu caráter. Eu sabia que, na avaliação dela, tinha garantidas uma vida segura, uma vida facilitada, uma boa educação, todas as oportunidades. Nunca teria de comer comida racionada, nem respeitar toques de recolher, nem assistir a tumultos de cima do telhado, nem esconder vizinhos nos tanques de água para impedir que fossem fuzilados, como ela e meu pai tinham feito (LAHIRI, 2014, p. 34). ${ }^{10}$

Todavia, ela só consegue perceber esses privilégios por conta dos discursos, aos quais ela é exposta em seu microcosmo familiar. A escola não a conscientiza para temáticas que se afastem do núcleo americano e nem tem a intenção de realizar esse processo. O papel da escola, nesse contexto, reside em estabilizar uma identidade nacional. Ao lado dessas duas fontes de informações históricas, ocorrem os acontecimentos que envolvem o Sr. Pirzada, cuja família está em meio ao conflito. A partir dessa perspectiva, ela reflete sobre como seria estar em uma situação semelhante, pois ela sabe que está segura em seu país. Desse modo, as narrativas históricas que assimila na escola continuam representando uma fonte de sentido para a identidade pessoal de Lilia, pois ela se percebe e se narra como americana, pertencente àquela

\footnotetext{
${ }^{10}$ Tradução nossa do original em língua inglesa.
} 
gênese de nação. Ao mesmo tempo, contudo, ela experimenta uma insuficiência, pois os acontecimentos históricos do contexto asiático também começam a revelar significância, pois impactam, em forma de sentido, em seu contexto familiar.

\section{CONSIDERAÇÕES FINAIS}

Os contatos com a história no conto Quando o Senhor Pirzada vinha jantar se dão a partir de dois eixos: de um lado, o confronto com os acontecimentos do contexto de origem da família da jovem Lilia e de outro, com a socialização com a história americana mediada pela escola que a menina frequenta. No primeiro eixo, a menina é confrontada por dois vetores: o discurso dos pais e as notícias midiáticas. De um lado, o discurso dos pais revela informações sobre a vida que conduziam e sobre as dificuldades enfrentadas em seu país de origem, contrastando com a vida que a filha desfruta nos Estados Unidos. O outro, relacionado com as notícias midiáticas que a menina vê com os pais e com o Sr. Pirzada, a confronta com acontecimentos atuais, que acarretam no desenvolvimento de sua consciência para assuntos mais delicados que não são abordados pela escola em que estuda.

Já no segundo eixo, Lilia é socializada com eventos históricos e elementos culturais importantes para o contexto americano, onde ela é exposta e treinada para afirmar uma determinada identidade nacional. Ou seja, a professora expõe as informações que ela considera relevantes para os alunos da escola e eles as fixam a partir de visitações a lugares históricos, avaliações e até mesmo em seus momentos de lazer. Nesse contexto escolar, o foco de ensino é voltado para a memorização de nomes importantes na história dos Estados Unidos. Nos dois casos, a história impacta sobre a identidade pessoal de Lilia em forma de sentido e a transforma, ao despertá-la para uma consciência do mundo em forma de pertencimento histórico. Ao encenar esse vetor de possíveis concretizações da existência humana, Jhumpa Lahiri capta uma importante experiência nesse percurso de tomada de consciência de indivíduos pertencentes ao contexto de fluxos migratórios.

\section{REFERÊNCIAS}

ADAMS, Bella. Asian American Literature. Edinburgh: Edinburgh University Press, 2008. 
BASAK, Shilpi. A Tryst with the Self: Migrancy, Diasporicity and Identity in Selected Short Stories of Jhumpa Lahiri. In: GIRI, Dipak (ed). Postcolonial English Literature: Theory and Practice. Nova Deli: Authorspress, 2018, p. 21-28.

DURAIRAJ, M. Exploring the Dichotomy of Diasporic Consciousness in the Female Characters of Jhumpa Lahiri's Interpreter of Maladies. In: BODHI, v. 2, p. 78-80, 2018.

LAHIRI, Jhumpa. Intérprete de Males. Tradução: José Rubens Siqueira. São Paulo: Biblioteca Azul, 2014.

MATHIAS, Dionei. Literatura e fluxos migratórios em contextos anglófonos: sobre a gênese discursiva de um campo de pesquisa. In: Scripta Uniandrade, v. 16, p. 225-238, 2018.

RAJESH, C.; RAJARAM, K. GIRIJA. Perspective views in Jhumpa Lahir's Interpreter of Maladies. In: Literary Endeavour, v. 1, p. 118-123, 2014.

STRAUB, Jürgen. Telling Stories, Making History. Toward a Narrative Psychology of the Historical Construction of Meaning. In: STRAUB, Jürgen (ed.). Narration, identity, and historical consciousness. New York: Berghan Books, 2005, p. 44-98. 